\title{
Arsenic in the hot springs in the Yunnan- Sichuan-Tibet Geothermal Province, China
}

\author{
Qinghai Guo, ${ }^{1, *}$ \\ ${ }^{1}$ State Key Laboratory of Biogeology and Environmental Geology \& School of Environmental \\ Studies, China University of Geosciences, 430074 Wuhan, Hubei, P. R. China
}

\begin{abstract}
The Yunnan-Sichuan-Tibet Geothermal Province (YST) in China is characterized by extremely high terrestrial heat flow and widely distributed hydrothermal systems, which are discharging geothermal waters with a wide range of arsenic concentrations. In this paper, the distribution of arsenic in the YST geothermal waters are presented, the general hydrochemistry of these waters is described, and the primary geochemical processes controlling the concentrations and speciation of geothermal arsenic in YST is considered.
\end{abstract}

\section{Introduction}

Arsenic (As) is an element with adverse environmental effects which occurs ubiquitously in geothermal waters though concentrations differ largely depending on tectonic settings [1]. In mainland China, surface geothermal manifestations have been found in every province. However, high-temperature hydrothermal systems with magmatic heat sources are distributed only in the Yunnan-Sichuan-Tibet Geothermal Province (abbreviated here as the YST Geothermal Province; Fig. 1), which is a major part of the Mediterranean-Himalayas geothermal belt. In the YST Geothermal Province, there are altogether 255 hydrothermal systems with reservoir temperatures higher than $150{ }^{\circ} \mathrm{C}\left(88^{\circ} \mathrm{C}\right.$ in western Yunnan, $38{ }^{\circ} \mathrm{C}$ in western Sichuan, and $129{ }^{\circ} \mathrm{C}$ in Tibet) according to estimations based upon chemical geothermometers [2].

As speciation in geothermal water is a topic of high current interest and deserving of investigation. The transformation between elemental As and arsenate upon change of redox potential has been well studied. Common knowledge is that arsenite is stable under anoxic, non-sulfidic conditions, and arsenate under oxic conditions. Abiotic oxidation of arsenite and reduction of arsenate are very slow, usually in the order of months [3], and, therefore, can also survive as metastable species under oxic and anoxic conditions, respectively. However, different from arsenite and arsenate, the trivalent thioarsenites are extremely labile in water and transform spontaneously back to arsenite (if $\mathrm{OH}^{-}>\mathrm{SH}^{-}$) or to (thio)arsenate(s) in the presence of even traces of oxygen $[4,5]$. In equilibrium, oxic conditions also lead to transformation of thioarsenates to arsenite or arsenate [6]. Slow transformation kinetics, however, enable metastable occurrence of thioarsenate even under oxic conditions [7]. These mechanisms well explain why thioarsenates containing both

\footnotetext{
* Corresponding author: qhguo2006@gmail.com
} 
oxidative $\mathrm{As}(\mathrm{V})$ and reductive $\mathrm{S}(-\mathrm{II})$ can be the predominant arsenic species in some neutral to alkaline hot springs under oxidizing conditions.

In this paper, we present the distribution of arsenic in the YST geothermal waters, describe the general hydrochemistry of these waters with a wide range of As concentration, and consider the primary geochemical processes controlling the concentrations and speciation of geothermal As across the YST.

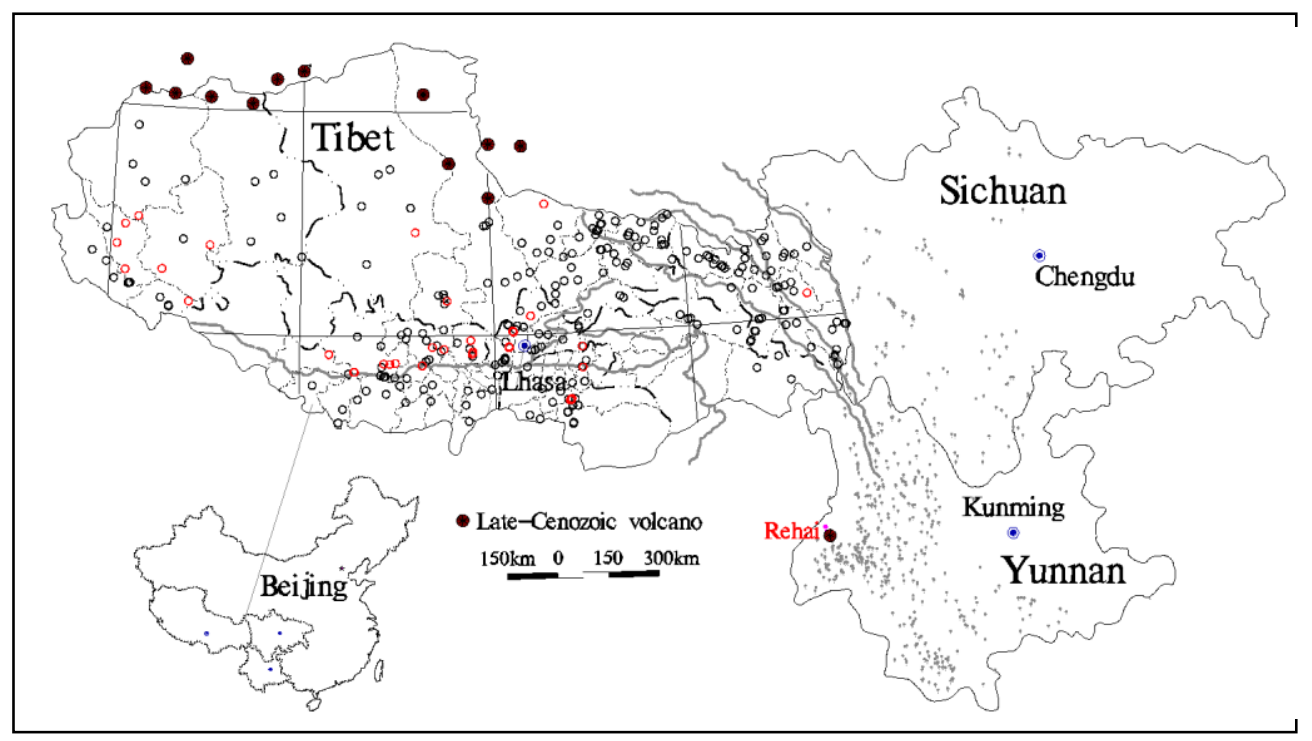

Fig. 1. Sampling locations in the Yunnan-Sichuan-Tibet geothermal Province (the sole hightemperature geothermal region in mainland China). Legend : $\odot$ : Tibetan geothermal waters with arsenic concentrations higher than $1.5 \mathrm{mg} / \mathrm{L}$; ○: Tibetan geothermal waters with arsenic concentrations lower than $1.5 \mathrm{mg} / \mathrm{L} ; \diamond:$ Rehai geothermal waters (all of them have arsenic concentrations lower than $1.5 \mathrm{mg} / \mathrm{L}$ ); $\diamond$ : Yunnan and Sichuan (excluding Rehai) geothermal waters (all of them except for one have arsenic concentrations lower than $1.5 \mathrm{mg} / \mathrm{L}$ ). Note that multiple samples collected from a single hydrothermal area with total area of several to several tens $\mathrm{km}^{2}$ cluster together and appear to be a single point on the map.

\section{Distribution of geothermal arsenic in YST}

In this study, besides the 61 geothermal water samples collected across Tibet by the author group with $\mathrm{pH}$ values ranging from 3.0 to 8.8 and Eh values from -353 to $83 \mathrm{mV}$, previous arsenic analyses of 381 Tibetan geothermal water samples collected by other investigators (299 from "Thermal springs in Tibet" [8] and 82 from "Final report for the development program of the geothermal resource at Yangbajing, Tibet, China" [9]) were also used for describing the distribution of geothermal As in Tibet. As concentrations of Tibetan geothermal waters vary greatly, from lower than the detection limit $(1 \mu \mathrm{g} / \mathrm{L})$ to $125.6 \mathrm{mg} / \mathrm{L}$. Out of 181 Tibetan water samples with As concentrations higher than $1.5 \mathrm{mg} / \mathrm{L}, 178$ are located in southern Tibet and exhibit an average concentration of $4.69 \mathrm{mg} / \mathrm{L}$. The three exceptions (Fig. 1) are the Daba hot spring (Changdu, eastern Tibet at $13.20 \mathrm{mg} / \mathrm{L}$ ), the Nuoermacuo hot spring (Naqu, northern Tibet at $6.40 \mathrm{mg} / \mathrm{L}$ ), and the Dazuo hot spring (Naqu, northern Tibet at $4.98 \mathrm{mg} / \mathrm{L}$ ). In contrast, among the 731 geothermal water samples in Yunnan and Sichuan (112 collected by the author group and the other 619 from "Thermal springs in Traverse Mountains region" [10]), only one sample has an As content $>1.5 \mathrm{mg} / \mathrm{L}$ - the Wenbi-1 spring in Dali (Yunnan) at $1.80 \mathrm{mg} / \mathrm{L}$. Intermediate arsenic 
concentrations (from 1 to $1.5 \mathrm{mg} / \mathrm{L}$ ) were almost all found together in one location - the Rehai system, a magmatic hydrothermal system in the Tengchong volcanic region of western Yunnan with an average As concentration from 54 analyses of $0.35 \mathrm{mg} / \mathrm{L}$ (Fig. 1; All other samples, except for the Wenbi-2 spring (Dali, Yunnan at $1.40 \mathrm{mg} / \mathrm{L}$ ) and the Yonganyan spring (Dali, Yunnan at $1.25 \mathrm{mg} / \mathrm{L}$ ), had concentrations lower than $1 \mathrm{mg} / \mathrm{L}$, with an average of $0.04 \mathrm{mg} / \mathrm{L}$ for 674 samples analysed.

The high-As $(>1.5 \mathrm{mg} / \mathrm{L})$ and relatively low-As $(<1.5 \mathrm{mg} / \mathrm{L})$ geothermal waters in Tibet have quite different hydrochemical characteristics. As shown in Fig. 2, the higharsenic waters are mostly of the chloride-type, whereas those low-arsenic waters are primarily bicarbonate-type and subordinately the sulfate-type (note that neutral, chloride/sodium-rich geothermal waters are typical for magmatic hydrothermal systems hosted by felsic rocks worldwide [11]). There are also some geothermal waters (either highor low-As) with comparable bicarbonate, sulfate and chloride concentrations. In the triangular diagram of $\mathrm{Na}-\mathrm{K}-\mathrm{Mg}^{1 / 2}$ (Fig. 3), the high-As geothermal waters are generally located in the partially equilibrated area with one sample plotting right on the full equilibrium line. In contrast, most low-As geothermal waters fall into the immature water area, and even those low-As waters within the partially equilibrated area are very close to the immature water area. This implies that the high-As waters are, or evolve from, deep geothermal fluids fully equilibrated with respect to Na-, $\mathrm{K}$ - and $\mathrm{Mg}$-bearing reservoir minerals, and the occurrence of such deep fluids indicates that these systems are very likely to be heated by magma chambers. However, the low-As geothermal waters, none of which are strongly acidic, are actually not immature water as defined by Giggenbach [11] to denote acid waters formed in hydrothermal systems - either acid waters directly evolving from magmatic fluid or steam-heated near-surface acid waters. These low-As waters plot in the immature water area just because they are relatively $\mathrm{Mg}$-rich due to various possible hydrogeochemical factors (e.g. they are affected by the leaching of reservoir carbonate rocks, their corresponding reservoir fluids never reach equilibrium with secondary $\mathrm{Mg}$ bearing minerals with low solubility at high temperatures (like chlorites), or they are substantially mixed by Mg-rich near-surface waters).

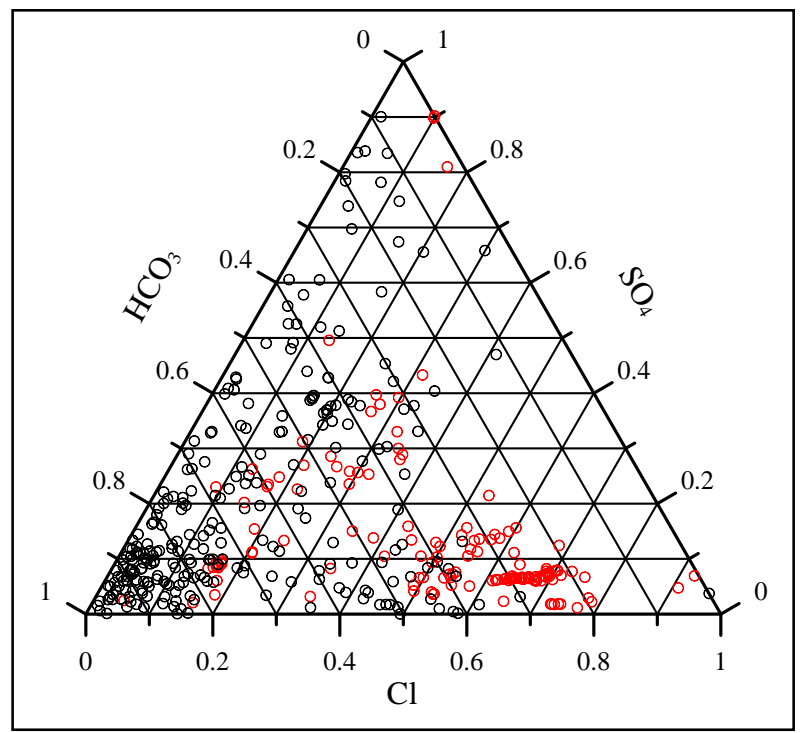

Fig. 2. Triangular diagram of $\mathrm{SO}_{4}, \mathrm{HCO}_{3}$ and $\mathrm{Cl}$ for all the Tibetan geothermal water samples. Legend of sample symbols: $\odot$, water samples with As concentrations higher than 1.5 $\mathrm{mg} / \mathrm{L} ; \circ$, water samples with As concentrations lower than $1.5 \mathrm{mg} / \mathrm{L}$. 


\section{Primary processes controlling the concentrations and speciation of geothermal arsenic in YST}

As presented before, concentrations of As vary greatly in different types of hot springs across the YST. Neutral $\mathrm{Na}-\mathrm{Cl}$ fluids are ubiquitous in the magmatic geothermal systems hosted by felsic rocks, and are commonly characterized by high concentrations of arsenic as well as undissociated $\mathrm{CO}_{2}$ and $\mathrm{H}_{2} \mathrm{~S}$. It is traditionally regarded that reducing conditions prevail in most geothermal reservoirs [12] and, therefore, the As therein occurs predominantly as arsenite. However, accumulating evidence suggests that the occurrence of sulfide in $\mathrm{Na}-\mathrm{Cl}$ hot springs, which are the direct discharge of deep $\mathrm{Na}-\mathrm{Cl}$ geothermal fluids after experiencing different cooling processes (typically adiabatic cooling or conductive cooling), favors the formation of thioarsenic species [7, 13]. These species can be either thioarsenites $\left(\mathrm{H}_{\mathrm{m}} \mathrm{As}^{\mathrm{III}} \mathrm{S}_{\mathrm{n}} \mathrm{O}_{3-\mathrm{n}}{ }^{\mathrm{m}-3} ; \mathrm{n}=1-3, \mathrm{~m}=0-3\right)$ formed from arsenite and sulfide or thioarsenates $\left(\mathrm{H}_{\mathrm{m}} \mathrm{As}^{\mathrm{V}} \mathrm{S}_{\mathrm{n}} \mathrm{O}_{4-\mathrm{n}}{ }^{\mathrm{m}-3} ; \mathrm{n}=1-4, \mathrm{~m}=0-3\right)$ formed from arsenite or thioarsenites by addition of elemental sulfur [14]. Pentavalent thioarsenates even dominate over arsenite and arsenate in the geothermal waters with very high sulfide concentrations. In fact, thioarsenates have been described to account for $>75 \%$ of total As in the surface geothermal waters in the Rehai hydrothermal area in YST [13]. In view of the critical role of sulfide in the formation of thioarsenic species and the volatility of sulfide under acid conditions, thioarsenic species were found more frequently at neutral to alkaline $\mathrm{pH}$ values.

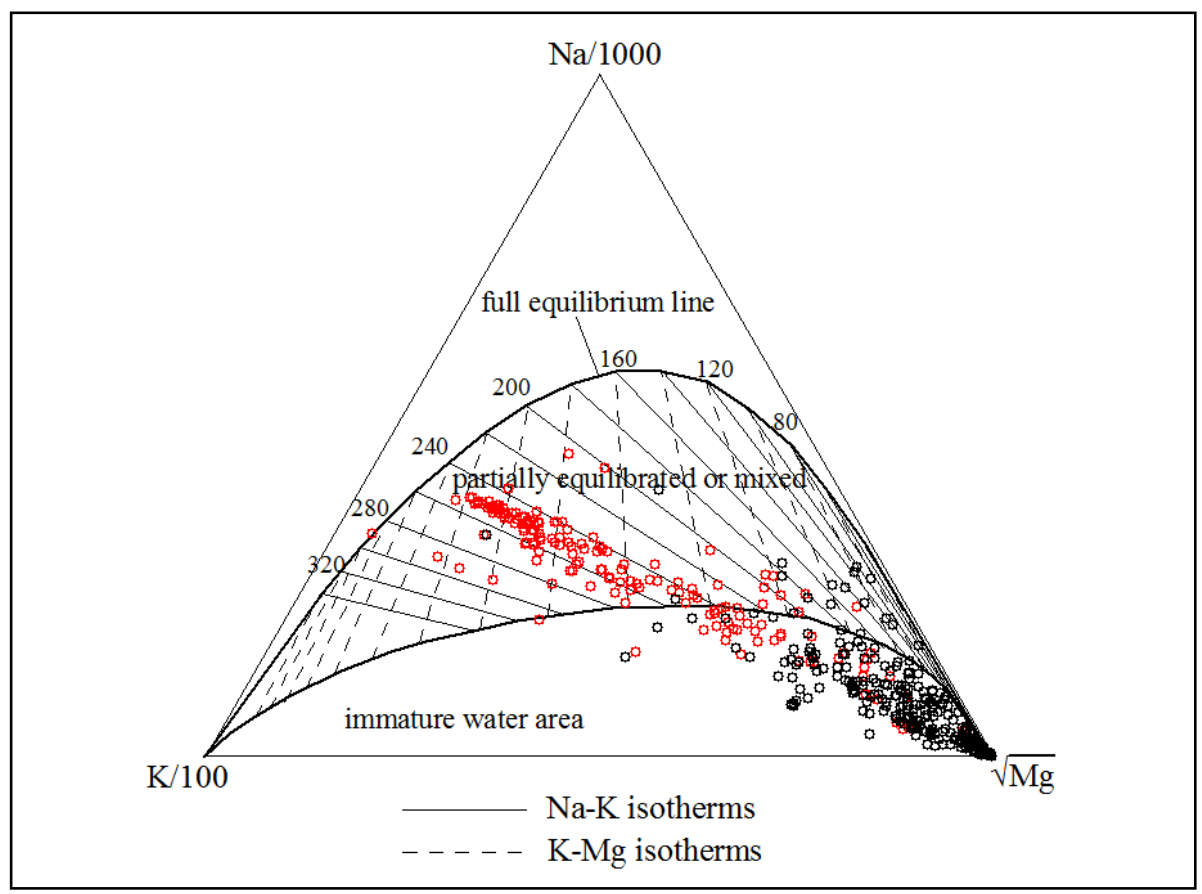

Fig. 3. Triangular diagram of Na-K-Mg ${ }^{1 / 2}$ for all the Tibetan geothermal water samples. Legend : $\circ$ - water samples with Asconcentrations higher than $1.5 \mathrm{mg} / \mathrm{L}$; $\bigcirc$ - water samples with As concentrations lower than $1.5 \mathrm{mg} / \mathrm{L}$.

Deep geothermal fluids may experience adiabatic cooling processes during ascent and be separated to neutral waters and geothermal vapors rich in $\mathrm{H}_{2} \mathrm{~S}$. If the separated geothermal $\mathrm{H}_{2} \mathrm{~S}$ were oxidized near the surface, acid sulfate hot springs containing elevated concentrations of $\mathrm{Fe}$ and $\mathrm{Al}$ can be formed. Upon oxidation, polysulfides, thiosulfate, and 
elemental sulfur are commonly formed as intermediate products $[15,16]$, but the final oxidation product is typically sulfuric acid. Therefore, these hot springs are characterized by low $\mathrm{pH}$, high concentrations of $\mathrm{SO}_{4}, \mathrm{Fe}$, and $\mathrm{Al}$, but low concentrations of As. In regard to arsenic speciation, arsenate is very likely to dominate, because this type of hot springs is essentially the discharge of locally-perched non-thermal groundwaters heated by deeplyderived geothermal vapors. In contrast, thioarsenic species are usually of very low concentrations. As speciation in acid steam-heated hot springs in the Rehai hydrothermal area indicates that all of these acid waters have low proportions of thioarsenic species compared to total As, mostly lower than $1 \%$ [13]. Interestingly, acidic $\mathrm{pH}$ conditions have also been confirmed to be adverse for the stability of thioarsenic species by laboratory studies [17]. According to a series of comprehensive experiments testing the $\mathrm{pH}$-dependent stability of thioarsenates [17], acidification is able to cause the conversion of tetra-, tri-, and partially di-thioarsenate to arsenite and the partial loss of total arsenic due to precipitation of arsenic-sulfur amorphous phases. Thus, owing to their acid instability, thioarsenates have previously often been overlooked even in sulfidic neutral or alkaline geothermal waters, because acidification, which was routinely used both for stabilization as well as for chromatographic separation, led to precipitation of As-S minerals [18] and transformation of thioarsenates to the oxyarsenic anions [17].

Furthermore, it is also worth noting that the mixing between acid sulfate geothermal waters and neutral chloride geothermal waters frequently occurs, resulting in the formation of geothermal waters with relatively high concentrations of both sulfate and chloride. This kind of waters is marked by variable As concentrations, depending on the As concentrations of their endmembers and the mixing ratio. The As speciation in these hot springs depends on residual sulfide contents. If sulfide is still rich, As is mainly present as arsenite and thioarsenates, whereas arsenate dominates in sulfide-deficient hot springs.

\section{Conclusions}

To summarize, for the geothermal systems hosted by felsic rocks in the Yunnan-SichuanTibet Geothermal Province, various hydrochemical types of hot springs can occur as a result of different reservoir processes. These hot springs are characterized by distinctive environmental physical and chemical conditions, e.g. temperature, $\mathrm{pH}$, redox potential, and oxygen and sulfide levels, which have vital impacts on aqueous arsenic concentration and speciation. In view of the importance of thioarsenic species in the widespread sulfidic geothermal waters, a deep understanding of the geochemical behaviors of thioarsenic species is crucial for investigating the transport, transformation and fate of geothermal arsenic in the environment.

\section{References}

1. A.J. Ellis, W.A.J. Mahon, Chemistry and Geothermal Systems, Academic Press, New York, 392 pp (1977)

2. Z. Liao, P. Zhao, Yunnan-Tibet Geothermal Belt-Geothermal Resources and Case Histories, Science Press, Beijing, 153 pp (1999)

3. R.B. McCleskey, D.K. Nordstrom, A.S. Maest, App Geochem, 19, 995-1009 (2004)

4. S. Stauder, B. Raue, F. Sacher, Env Sci Tech, 39, 5933-5939 (2005)

5. B. Planer-Friedrich, et al., Anal Chem, 82, 10228-10235 (2010)

6. B. Planer-Friedrich, et al., Geomicrobiolo J, 26, 339-350 (2009)

7. B. Planer-Friedrich, et al., Env Sci Tech, 41, 5245-5251 (2007) 
8. W. Tong, et al., Thermal springs in Tibet, Science Press, Beijing, 300 pp (2000)

9. JICA \& TEPC, Final report for the development program of the geothermal resource at Yangbajing, Tibet, China, (2006)

10. W. Tong, M. Zhang, Thermal springs in Traverse Mountains Region, Science Press, Beijing, 326 pp (1994)

11. W.F. Giggenbach, Geochim Cosmochim Acta, 52, 2749-2765 (1988)

12. J.G. Webster, D.K. Nordstrom, Geothermal arsenic, in Arsenic in Ground Water, Kluwer Academic Publishers, Boston, 101-125 (2003)

13. Q. Guo, et al., Chem Geol, 453, 12-20 (2017)

14. B. Planer-Friedrich, et al., Env Sci Tech, 49, 6554-6563 (2015)

15. Y. Xu, et al., Geochim Cosmochim Acta, 62, 3729-3743 (1998)

16. Y. Xu, et al., J Volcano Geoth Res, 97, 407-423 (2000)

17. B. Planer-Friedrich, D. Wallschläger, Env Sci Tech, 43, 5007-5013 (2009)

18. J.A. Smieja, R.T. Wilkin, J Env Monit, 5, 913-916 (2003) 